\title{
Prácticas de textualidad digital de bachilleres al tomar notas sobre diccionarios en línea en la mediateca de lenguas
}

\section{Digital textuality practices of high school students when taking notes on Online Dictionaries in the language media library}

\author{
Ernesto Hernández Rodríguez ${ }^{1}$ \\ ernestotem@live.com.mx \\ Universidad Nacional Autónoma de México \\ Campus Escuela Nacional Preparatoria
}

\section{Resumen:}

INTRODUCCIÓN. Este estudio caracteriza las prácticas de textualidad digital de 18 estudiantes de bachillerato al tomar notas en el procesador de textos Word, sobre diccionarios en línea, monolingües en español e inglés y bilingües, inglés-español y español-inglés. Los alumnos exploraron los diccionarios y, para conocerlos, realizaron la consulta del verbo en inglés get. El enfoque corresponde a la literacidad en la textualidad digital. MÉTODO. El estudio contempla la identificación de recursos multimedia y modalidades de textualidad en los diccionarios, y la descripción de la escritura digital en los apuntes. El análisis textual involucra criterios de informatividad identificados en los diccionarios: usos de la lengua, consultas digitales, diseños textuales, fuentes de intertextualidad, coherencia e interactividad, así como la cohesión digital en la redacción expositiva y descriptiva, la intertextualidad mediante ilustraciones, hipervínculos y referencias

\begin{abstract}
:
INTRODUCTION. This paper reports on the digital practices of 18 high school students' when taking notes with the text processor Word about the characteristics of on-line dictionaries-Spanish and English monolingual dictionaries and English-Spanish and Spanish-English bilingual dictionaries. The students explored the dictionaries and, in order to get familiar with them, they worked with the English verb get. The approach implemented refers to literacy in digital textuality. METHOD. The study contemplates the identification of multimedia resources and textual modalities in the dictionaries and the description of digital writing in the notes. Classification and textual analysis involves the informativity criteria identified in the dictionaries: language use, digital searches, textual designs, intertextuality sources, coherence and interactivity, as well as digital cohesion in descriptive and expositive writing, intertextuality by means of images, hyper-
\end{abstract}

1 Dirección para correspondencia (correspondence address):

Ernesto Hernández Rodríguez. Universidad Nacional Autónoma de México, Escuela Nacional Preparatoria. Emiliano Zapata 18, Guadalupe Victoria Cuautepec. 07209, Ciudad de México (México). 
Prácticas de textualidad digital de bachilleres al tomar notas sobre diccionarios en línea en la mediateca de lenguas

Ernesto Hernández Rodríguez

léxicas y gráficas. RESULTADOS. Los apuntes evidencian el predominio en la identificación de herramientas prácticas en los diccionarios, y menor atención en la coherencia y la interactividad, así como dificultades para integrar la redacción expositiva y descriptiva con las modalidades digitales de intertextualidad, hipertextualidad y referencialidad. DISCUSIÓN. La consideración e identificación de diversos aspectos de textualidad en los diccionarios exhiben la variedad en la intencionalidad y el desempeño mediante recursos digitales y multimodales. Sin embargo, es necesario el apoyo docente y la práctica para apreciar de manera integral la información, así como para la redacción digital en los apuntes.

\section{Palabras clave:}

Textualidad digital; internet; diccionarios; apuntes; multimedia; modalidad. links and lexical and graphic references. RESULTS. The notes show a predominant use of practical tools in the dictionaries in comparison to coherence and interactivity. They also evidence difficulties to integrate expositive and descriptive writing with digital modalities of intertextuality, hypertextuality and referentiality. DISCUSSION. Consideration and identification of various aspects of textuality in dictionaries show various degrees of intentionality and performance through digital and multimodal resources. However, teaching and practice support is necessary to fully appreciate the information, as well as the digital writing in notes.

\section{Keywords:}

Digital textuality; internet; dictionaries; notes; multimedia; modality.

\section{Résumé:}

INTRODUCTION. Cet article présente une caractérisation des pratiques de textualité numérique de 18 élèves du secondaire quand ils prennent des notes avec le processeur de textes Word, sur les caractéristiques des dictionnaires en ligne, monolingues en espagnol et anglais et bilingues anglais-espagnol et espagnol-anglais. Les élèves ont exploré des dictionnaires: pour les connaître, ils ont consulté le verbe anglais get "obtenir". L'étude envisage la perspective de l'alphabétisation dans la textualité numérique. MÉTHODE. L'étude prévoit l'identification des ressources multimédias et les modalités de la textualité dans les dictionnaires, et ainsi que la description des notes d'écriture numérique. L'analyse textuelle implique des critères d'informativité identifiés dans les dictionnaires: utilisations de la langue, consultations numériques, dessins textuels, sources d'intertextualité, la cohérence, l'interactivité et la cohésion numérique dans l'écriture descriptive et d'exposition, l'intertextualité à travers des illustrations, les liens hyperliens et les références lexicales et graphiques. RÉSULTATS. Les notes montrent la prédominance de l'identification des outils pratiques dans les dictionnaires et moins d'attention à la cohérence et à l'interactivité, ainsi que des difficultés à intégrer l'écriture explicative et descriptive avec les modalités numériques d'intertextualité, d'hypertextualité et de référentialité. DISCUSSION. La prise en compte et l'identification de divers aspects de la textualité dans les dictionnaires montrent la variété de l'intentionnalité et de la performance à travers les ressources numériques et multimodales. Cependant, un soutien pédagogique et pratique est nécessaire pour apprécier pleinement les informations, ainsi que pour l'écriture numérique dans les notes.

Mots-clés: textualité numérique, internet, dictionnaires, notes, multimédia, modalité

Fecha de recepción: 05-07-2018

Fecha de aceptación: 27-11-2019 


\section{Introducción y antecedentes}

Los estudiantes de Bachillerato se ven en la necesidad de realizar prácticas de lectura y escritura mediante las Tecnologías de la Información y la Comunicación, empleando recursos multimedia y multimodales en un contexto de textualidad digital. Estas prácticas implican desarrollar habilidades que involucran, además del uso operativo de las herramientas y funciones de la tecnología empleada, el reconocimiento y el manejo integral de las modalidades de literacidad digital en los contenidos, la coherencia, la cohesión, la intertextualidad, la hipertextualidad y la referencialidad. Para usar los diccionarios en línea, se requiere aprender a reconocer y emplear los diversos diseños, herramientas, recursos y posibilidades de consulta. Asimismo, en la toma de notas, en un procesador textos, sobre las características de estas fuentes textuales, los estudiantes necesitan desarrollar el conocimiento y la práctica de la redacción en la textualidad digital.

Esta investigación contempla como antecedentes los enfoques de la lectura y la escritura en sus manifestaciones multimedia y multimodales mediante las Tecnologías de la Información y la Comunicación (Jewitt, 2006; Lea y Jones, 2010; Edwards-Groves, 2010; Olza, 2014; BlikstadBalas, 2015). Derivado de la contextualización de los estándares clásicos de textualidad (De Beugrande y Dressler, 1997) en el marco de literacidad digital, el trabajo considera los criterios de informatividad y cohesión digital para caracterizar la escritura de apuntes, en el procesador de textos Word, sobre los diccionarios en línea consultados.

Las siguientes secciones presentan el objetivo general y los particulares, el enfoque de prácticas y criterios de escritura en la textualidad digital, la caracterización de los estudiantes, la metodología para propiciar la escritura de los apuntes sobre los diccionarios en línea y las categorías de análisis en términos de criterios de informatividad y cohesión digital. El trabajo continúa con los resultados, la discusión, los ejemplos representativos de los apuntes digitales y las conclusiones.

\section{Objetivos}

El objetivo general del trabajo es estudiar las prácticas de textualidad digital de 18 estudiantes de Bachillerato, en una de las actividades 
Prácticas de textualidad digital de bachilleres al tomar notas sobre diccionarios en línea en la mediateca de lenguas

ERnesto Hernández Rodríguez

del taller de inducción a la mediateca de lenguas, al tomar notas en el procesador de textos sobre las características de diccionarios en las modalidades monolingüe en inglés y español y bilingüe inglés-español, español-inglés, con la idea de conocer y compartir sus características y aplicaciones en el aprendizaje y uso de las lenguas.

Los objetivos particulares comprenden la clasificación, caracterización y análisis de los apuntes sobre los diccionarios en línea, mediante una propuesta de criterios y categorías de textualidad digital para describir la coexistencia de recursos multimedia y multimodales en la expresión escrita y en los recursos gráficos en el entorno digital.

Los alumnos trabajaron en un menú de hipervínculos a distintos diccionarios. A continuación, realizaron consultas del significado de la palabra get y tomaron notas sobre las características y apreciaciones de los diccionarios y sobre el ejercicio práctico de consulta.

Se justifica este trabajo por la necesidad de conocer, mediante criterios integrales de textualidad, las prácticas de los estudiantes en la consulta de diccionarios en línea y en la toma de apuntes en el procesador de textos. Asimismo, es fundamental realizar estas actividades de manera contextualizada con acervos educativos, con el propósito de fomentar la consulta de diversas fuentes textuales y enriquecer la diversidad de prácticas de textualidad digital de los estudiantes.

\section{Enfoque teórico}

La revisión, valoración y comparación de diccionarios en Internet para tomar notas sobre sus características, en el procesador de textos, involucra prácticas de textualidad discursivas y digitales de naturaleza multimodal, de interés para esta investigación. El estudio de la comunicación mediante tecnologías de la comunicación y la información centra su atención en la caracterización de la lectura y la escritura en los soportes y formatos digitales y sus manifestaciones multimodales y multimedia.

El trabajo contempla el enfoque de la textualidad digital en los desempeños textuales y discursivos mediante la multiplicidad de prácticas y estrategias correspondientes a literacidades digitales (Lea y Jones, 2010; Blikstad-Balas, 2015). El estudio considera la coexistencia de manifestaciones multimedia y multimodales digitales de lectura y escritura (Jewitt, 2006; Edwards-Groves, 2010; Olza, 2014, López, 2017). Esta investi- 
gación adapta y contextualiza, en el marco de la literacidad digital, los estándares clásicos de textualidad (De Beugrande y Dressler, 1997)².

La expresión digital presenta la información mediada por los soportes físicos de las tecnologías, por ejemplo, en pantallas, teclados, dispositivos y accesos a Internet. Las manifestaciones digitales se expresan en las opciones multimedia, por ejemplo, audios, videos, procesadores de texto, hipervínculos, programas y páginas de Internet. Estos recursos propician el desarrollo de manifestaciones multimodales del desempeño textual y discursivo, como resultado de prácticas de textualidad digital (Álvarez, González y Bassa, 2017).

En los apuntes mediante el procesador de textos Word, los alumnos requieren aplicar criterios textuales relacionados con los soportes y modalidades digitales, por ejemplo, los formatos, el manejo de la información, la intertextualidad en las consultas y la cohesión textual. En la escritura digital, Johnson y Nádas (2009) y Stacy y Cain (2015) estudian los apuntes con las nuevas tecnologías de la información. Para caracterizar los apuntes en el procesador de textos Word sobre los diccionarios en línea, este trabajo contempla los siguientes criterios de textualidad digital.

- Informatividad: Este criterio está relacionado con la selección, valoración y sistematización de los contenidos (De Beugrande y Dressler, 1997). En la toma de apuntes sobre los diccionarios en línea, los alumnos contemplan contenidos relacionados con los recursos y prácticas de textualidad digital identificados en estas fuentes de consulta.

- Coherencia: Se refiere al sentido claro de los contenidos y la intencionalidad expresada. La información, proveniente de múltiples fuentes multimedia, puede producir dificultades en la coherencia. Tyrkkö (2007) considera que en la lectura y la escritura digital, el predominio de la fragmentación de la información y la ambigüedad referencial afecta la coherencia.

- Cohesión: En la tradición clásica (Halliday y Hassan, 1976; De Beugrande y Dressler, 1997), la cohesión produce la articulación y la armonía en los recursos gramaticales, discursivos, los elementos de transición, enlace y referencia a determinados contenidos. Los

2 Estándares clásicos de textualidad (De Beugrande y Dressler 1997): informatividad (contenidos), cohesión (articulación y estructuración de recursos textuales), coherencia (claridad en la información), intencionalidad (propósito comunicativo), intertextualidad (relación del escrito con otros textos), adecuación (pertinencia del lenguaje) y situacionalidad (contexto). 
Prácticas de textualidad digital de bachilleres al tomar notas sobre diccionarios en línea en la mediateca de lenguas

ERnesto Hernández Rodríguez

medios digitales propician la coexistencia multimodal de elementos cohesivos sintácticos, discursivos, gráficos y vínculos a distintas fuentes textuales (Edwards-Groves, 2010; Olza, 2014; Cordón, 2016).

- Intertextualidad: Involucra las relaciones de un escrito con otros textos o fuentes de información (De Beugrande y Dressler, 1997). La textualidad digital presenta intertextutalidad multimodal mediante accesos y referencias léxicas o gráficas a las fuentes de interés. La hipertextualidad es una modalidad de intertextualidad referencial de acceso directo a determinado texto, mediante enlaces a opciones multimedia, por ejemplo, un documento en pdf, audios, imágenes, videos y páginas de internet. Cerić (2013) aborda las relaciones de intertextualidad como elementos fundamentales de la interactividad digital y las relaciones dialógicas.

- Diseños textuales: En los diccionarios digitales, los estudiantes acceden a distintos modos de distribución de la información en entradas léxicas, imágenes e hipervínculos. Los diseños, formatos y recursos gráficos en línea permiten la interacción digital mediante tablas, diagramas, imágenes, distribuciones espaciales y entornos de la textualidad en línea. Gurr (1999), Johnson y Nádas (2009), Whitman (2009) y Waller (2012) exploran el diseño diagramático, espacial y de formatos en la estructuración del texto digital.

- Interactividad dialógica: La representación textual de los interlocutores propicia la interactividad dialógica mediante recursos digitales para intentar la inclusión de los lectores (Hyland, 2005), la posibilidad dialógica de retroalimentación (Sarena, 2006), la comunicación interpersonal (Serrano-Puche, 2013) y la sensación dialógica en el diseño de materiales digitales (Hernández y Reyes, 2015a).

- Interactividad mecánica: Este criterio corresponde al manejo operativo de los dispositivos físicos de la tecnología empleada. Coyle y Thorson (2001) conciben la interactividad mecánica en el control de las herramientas para el flujo de la información en contexto, y Mayer $(2002$, p. 61) la contempla al considerar que se aprende mejor al tener el control del material multimedia.

Asimismo, en la textualidad multimodal digital están presentes los estándares o criterios clásicos de adecuación en la pertinencia de con- 
tenidos en determinado contexto y el de intencionalidad en el propósito de quien intenta comunicarse. Esta propuesta de criterios de textualidad digital permitió crear categorías para estudiar las prácticas de literacidad mediante las tecnologías multimedia y las manifestaciones multimodales en los planos lingüísticos, discursivos, gráficos, diagramáticos, hipertextuales y referenciales.

\section{Metodología}

\subsection{Los estudiantes participantes}

Participaron 18 estudiantes de un promedio de 17 años, del nivel intermedio de inglés del tercer ciclo escolar, en las sesiones de inducción a la mediateca de lenguas de la Escuela Nacional Preparatoria 3, al norte de la Ciudad de México, para conocer las actividades y el acervo impreso y digital. La mediateca ofrece talleres y asesorías para fomentar el aprendizaje autorregulado de la lengua (Wenden, 1986; Oxford, 1990; Bausela-Herreras, 2007). El propósito del taller era revisar y usar los diccionarios en línea, así como tomar notas sobre sus características. La lengua de instrucción fue el español y no había prerrequisito sobre el nivel de dominio del inglés.

\subsection{Diseño y prácticas de elicitación}

El trabajo se realizó a partir del diseño de un menú de hipervínculos a los siguientes diccionarios en línea: Oxford Learners' Dictionary, Merriam Webster, Cambridge Dictionary Online, Merriam Webster Learners' Dictionary, Merriam Webster Visual Dictionary, WordReference, Oxford Dictionary, Collins, Diccionario Larousse ilustrado y Diccionario de la Real Academia Española ${ }^{3}$. Estos hipervínculos a las fuentes de consulta forman parte de un blog, como recurso de apoyo para la redacción bilingüe y la traducción escolar. En esta ocasión, los alumnos únicamente trabajaron en la sección de diccionarios en inglés.

3 Consultar el "Manual de Recursos para la redacción bilingüe" en la sección del menú de diccionarios (Hernández y Reyes, 2015b).

https://recomendacionesbilingues.blogspot.com/2015/10/800x600-normal-0-21-false-false-false_93.html 
Prácticas de textualidad digital de bachilleres al tomar notas sobre diccionarios en línea en la mediateca de lenguas

ERnesto Hernández RodríGuez

El trabajo contempla las prácticas metodológicas que incluyen las actividades y la interacción con los estudiantes, correspondientes a las técnicas de elicitación para tratar de propiciar la producción lingüística de interés para el investigador (Gass y Mackey, 2007; Hyland, 2016), en esta ocasión, escribir en el procesador de textos sobre los recursos de textualidad digital identificados en los diccionarios consultados.

El trabajo inició con una primera sesión de 50 minutos dedicada a la revisión panorámica del menú de diccionarios y después los estudiantes los exploraron individualmente. Para conocerlos en la práctica, realizaron la consulta del verbo get; todos dijeron conocerlo y estuvieron de acuerdo en sus múltiples usos" ${ }^{\prime 4}$. El propósito era emplear este verbo por su diversidad de significados, e identificar y valorar la manera en que aparece en las distintas fuentes consultadas. Al finalizar la sesión, nos reunimos y los alumnos comentaron sus apreciaciones sobre los diccionarios explorados y las consultas realizadas en ellos. Acordamos que la siguiente sesión estaría dedicada a realizar apuntes sobre los diccionarios revisados.

Iniciamos la segunda sesión comentando, de manera grupal, las ventajas y limitaciones de la corrección ortográfica y gramatical mediante el procesador de textos Word y la necesidad de contextualizarlo en la práctica. Estuvimos de acuerdo en que este corrector digital no distingue todos los errores, por ejemplo, la acentuación del sustantivo inglés (idioma) e ingles (parte del cuerpo). Comentamos la importancia de la revisión cuidadosa mediante este procesador de textos, y, ante posibles, dudas emplear el diccionario ${ }^{5}$. Escribimos otros ejemplos y constatamos la limitación de esta herramienta y lo fundamental de una revisión reflexiva, por ejemplo, en "mi amigo (público-publico-publicó)" y "ella (cálculo-calculó-calculo)".

A continuación, los estudiantes recibieron la instrucción de revisar individualmente los diccionarios en línea y experimentar libremente búsquedas de palabras y sus significados. A continuación escribieron un apunte, en el procesador de textos Word, sobre las características de los diccionarios, con la idea de darlos a los conocer en la mediateca. Con el propósito de monitorear la actividad, los estudiantes recibieron apoyo

4 Las consideraciones de los alumnos sobre este verbo son motivo de otra investigación en curso. En esta ocasión, el interés se centró en las prácticas de textualidad digital al tomar notas sobre los diccionarios.

5 El "Manual de recursos para la redacción bilingüe" (Hernández y Reyes, 2015b) incluye los diccionarios en línea de la Real Academia y Larousse para el español. 
ante posibles dudas y dificultades al manejar el equipo, explorar las diversas opciones del menú, realizar consultas y emplear el procesador de textos para la redacción y el uso de recursos gráficos.

En general, los estudiantes comenzaron experimentando dificultades para expresar por escrito sus consideraciones sobre los diccionarios. Con la idea de propiciar la expresión en los apuntes, cuando fue necesario recibieron apoyo individualmente sobre las propiedades de las fuentes consultadas, sus características, ventajas y comparaciones entre distintas opciones del menú.

El énfasis en el seguimiento de la actividad fue apoyar a los estudiantes en la escritura descriptiva de las características de los diccionarios, mediante la diversidad de recursos gráficos y de redacción con el procesador de textos. Por ello, cuando un estudiante se limitaba simplemente a mencionar una impresión de determinado diccionario, recibió la sugerencia de explicar su respuesta mediante ejemplos y detalles de las herramientas de dicha fuente. Una vez que los estudiantes se ambientaron a esta dinámica de trabajo, lograron trabajar en la escritura de los apuntes. Entonces, el monitoreo de la actividad se centró en el seguimiento, el asesoramiento para realizar los apuntes y resolver posibles dudas. Finalmente, 7 estudiantes terminaron sus apuntes en esta sesión, 9 en la siguiente y 2 decidieron completarlos en casa y enviarlos por correo electrónico.

\subsection{Criterios de clasificación y análisis}

El método de descripción textual comenzó con la clasificación de los apuntes conforme al criterio de informatividad, mediante la siguiente propuesta de contenidos identificados en los diccionarios:

Usos de la lengua: léxico, pronunciación, traducciones, versiones bilingües, conjugaciones, gramática, explicaciones y ejercicios.

Consultas digitales: El acceso a la información mediante el buscador y el menú de consultas.

Diseños y secciones textuales: Las formas y formatos para presentar la información y las partes del diccionario en determinada distribución y entorno de textualidad digital.

Intertextualidad: La relación entre distintas fuentes textuales mediante hipervínculos y referencias a imágenes y textos.

Coherencia: La claridad de los contenidos en la modalidad digital. 
Prácticas de textualidad digital de bachilleres al tomar notas sobre diccionarios en línea en la mediateca de lenguas

ERnesto Hernández RodríGuez

Interactividad dialógica: La interacción en las consultas y en redes sociales.

Interactividad mecánica: La manera operativa de trabajar con el equipo y los recursos multimedia.

El método de estudio descriptivo de los apuntes contempló categorías de clasificación y análisis mediante el criterio de cohesión textual, manifestado en los siguientes recursos de discursividad digital mediante el procesador de textos:

Expositivo-descriptivo: El recurso discursivo de redacción para exponer y describir.

Intertextualidad mediante ilustraciones: Imágenes para explicar o ilustrar lo redactado.

Intertextualidad mediante hipervínculos: Manejo de ligas o vínculos para el acceso directo a determinada fuente textual.

Referencialidad léxica a lo redactado: Relación léxica que remite a información escrita.

Referencialidad léxica a las ilustraciones: Relación léxica que remite a una imagen.

Referencialidad gráfica. Recurso gráfico que remite a lo escrito o a una imagen.

Estos criterios permitieron caracterizar los apuntes, mediante prácticas discursivas de cohesión digital, correspondientes a la redacción expositiva y descriptiva, la intertextualidad y la referencialidad en las modalidades de escritura con el procesador de textos.

\section{Resultados y discusión}

\subsection{Criterios de informatividad contemplados en los diccionarios en línea}

En las notas digitales sobre las características de los diccionarios en línea, podemos apreciar los elementos correspondientes al criterio de informatividad en los contenidos (De Beugrande y Dressler, 1997), relacionados con los usos y recursos digitales, tal como muestra la Tabla 1. 
Prácticas de textualidad digital de bachilleres al tomar notas sobre diccionarios en línea en la mediateca de lenguas ERnesto HeRnández RodríGuez

Tabla 1

Elementos de informatividad contemplados en los diccionarios en línea

\begin{tabular}{ll}
\hline $\begin{array}{l}\text { Aspectos identificados en } \\
\text { los diccionarios en línea }\end{array}$ & Ocurrencias en los apuntes digitales \\
\hline Usos de la lengua & $17(1,2,3,4,5,6,7,8,9,10,11,12,13,14$, \\
& $15,16,17,18)$ \\
\hline Consultas digitales & $16(1,2,3,5,6,7,8,9,10,11,12,13,14$, \\
& $15,16,17)$ \\
\hline Recursos multimedia & $16(1,2,3,5,6,7,8,9,10,11,12,13,14$, \\
& $15,16,17,18)$, \\
\hline Fuentes de intertextualidad & $13(2,3,6,7,8,9,10,11,12,13,14,15,18)$ \\
\hline Diseños y secciones textuales & $10(4,6,7,8,9,10,13,14,15,17)$ \\
\hline Coherencia & $9(1,2,3,4,6,10,12,16)$ \\
\hline Interactividad dialógica & $5(1,7,9,13,17)$, \\
\hline Interactividad mecánica & $5(2,6,8,9,17)$ \\
\hline
\end{tabular}

Los datos muestran el predominio en la identificación de usos de la lengua en los diccionarios, las consultas digitales y los recursos multimedia. Es posible observar esta situación en los siguientes ejemplos ${ }^{7}$.

\section{Texto $17 \mathrm{H}$ \\ Uso de la lengua:}

Cambridge Dictionary: [...] puedes encontrar la conjugación de la palabra en tiempos diferentes. [...] no debe faltar el audio de la pronunciación. Como la palabra es realmente usada en muchas oraciones y tiene varios significados, Cambridge Dictionary te deja ver ejemplos y en qué tipo de oraciones utiliza. [...]

Consultas digitales:

Oxford: [...] pondremos un ejemplo de búsqueda con la palabra "get" y ver las herramientas [...] Empezamos con una herramienta muy servible: "LISTENING" Y "PRONUNCIATION". No sólo vamos a saber la definición de la palabra, también aprenderemos como se pronuncia y se escucha en persona nativa $[\ldots]$

6 En paréntesis aparece el número asignado al apunte correspondiente.

7 En los ejemplos se respeta la redacción de los estudiantes. Sin embargo, para facilitar la lectura del artículo, la ortografía, la acentuación y el uso de mayúsculas aparecen normalizadas. Únicamente cuando se ejemplifican este tipo dificultades al escribir mediante el procesador de textos, no se hacen las correcciones correspondientes. 
Prácticas de textualidad digital de bachilleres al tomar notas sobre diccionarios en línea en la mediateca de lenguas

ERnesto Hernández RodríGuez

\section{Recursos multimedia}

Collins [...] da la oportunidad de ver un video donde explican cómo se pronuncia y que tan frecuente las personas utilizan esta palabra [...]

Cambridge Dictionary: [...] una herramienta interesante que ofrece este diccionario es la oportunidad de escuchar la pronunciación de la palabra [...]

La identificación predominante de herramientas y manejos prácticos (usos de la lengua, consultas digitales y recursos multimedia) evidencia la consideración de criterios y funciones fundamentales para utilizar los diccionarios. Sin embargo, los estudiantes mostraron dificultad para identificar los demás aspectos: fuentes de intertextualidad, diseños y secciones textuales, coherencia e interactividad dialógica y mecánica. Por ello, resultaba fundamental el posterior trabajo con estas fuentes de consulta. Esta situación puso de manifiesto la caracterización del conjunto de estrategias de literacidad digital (Lea y Jones, 2010; Blikstad-Balas, 2015) y prácticas de textualidad digital (Álvarez, González y Bassa, 2017), en este caso, en el ambiente escolar del bachillerato.

El desempeño para identificar la intertextualidad al relacionar fuentes textuales (13 de 18), muestra la necesidad de los alumnos a ambientarse a este recurso de textualidad, como elemento fundamental de la interactividad y establecimiento de relaciones con distintas informaciones (Cerić, 2013). En el siguiente ejemplo, el alumno destacó la intertextualidad en el diccionario.

\section{Texto $18 \mathrm{M}$.}

Intertextualidad

WordReference: [...] Como podemos observar tiene enlaces a otros diccionarios, creo que es útil porque tiene la traducción y puedes guiarte de otros para complementar tu información. [...]

La atención prestada a los diseños y secciones textuales (10 de 18) evidencia la dificultad para reconocer diversos formatos textuales. Whitman (2009) y Waller (2012) contemplan este tipo de manifestaciones multimedia y multimodal en el diseño y estructuración del texto digital. Así, en el siguiente ejemplo, el alumno destacó el diseño para el manejo de contenidos mediante un índice. 


\section{Texto $17 \mathrm{H}$}

Diseños y secciones textuales

Collins: [...] al principio de la página tiene como un tipo de índice con la finalidad de que la búsqueda sea más funcional o rápida.

La reducida identificación de la coherencia digital (9 de 18) muestra la dificultad para determinar la claridad de los contenidos. Los siguientes ejemplos destacan la claridad y, por otra parte, la confusión en los diccionarios consultados.

\section{Texto $6 \mathrm{M}$}

Merriam-Webster: [...] la conjugación que presentan aquí es más clara pero la manera de usar la palabra son menos claras que en la anterior [...]

\section{Texto $10 \mathrm{H}$}

Visual Merriam Webster: Esta página es muy confusa y tediosa realmente cuando pones en el buscador la palabra que deseas traducir no sale ningún resultado [...] tampoco vienen instrucciones de como buscar [...] en verdad que es complicado saber cómo.

Esta situación corresponde a la problemática observada por Tyrkkö (2007) en la comunicación digital, sobre la tendencia a la descontextualización y la fragmentación de la información, y, por ende, la ambigüedad referencial y las dificultades en la lectura y la escritura.

En su mayoría, los alumnos no consideraron los recursos de interacción dialógica (5 de 18) en el diseño de los diccionarios, las consultas ni en la comunicación en Internet. De esta forma, resultaba fundamental propiciar la retroalimentación, la sensación dialógica (Sarena, 2006; Hernández y Reyes, 2015a) y la comunicación interpersonal (SerranoPuche, 2013). El ejemplo $7 \mathrm{H}$ contempla la interactividad en la red digital y el $17 \mathrm{H}$ la necesidad de interactuar y "Ilamar la atención" de los usuarios. 
Prácticas de textualidad digital de bachilleres al tomar notas sobre diccionarios en línea en la mediateca de lenguas

ERnesto Hernández RodríGuez

\section{Texto $7 \mathrm{H}$}

Oxford: [...] seguimos viendo publicidad [...] además de contar con la facilidad de compartirlo con tus amigos por medio de redes sociales.

\section{Texto $17 \mathrm{H}$}

Cambridge Dictionary: Lo malo de este diccionario es que no tiene algo que haga Ilamar la atención del público. A diferencia de las demás páginas en internet, esta es apagada, sencilla y te llega a aburrir.

La mayoría de estudiantes tampoco prestó atención a la interactividad mecánica (5 de 18), es decir, el manejo operativo del equipo. En la perspectiva de Coyle y Thorson (2001) y Mayer (2002, p. 61), es fundamental el control de las herramientas, experimentar con ellas para lograr el flujo de la información y la interacción. En los siguientes ejemplos, los estudiantes contemplaron el modo de usar los recursos y las herramientas digitales.

\section{Texto $9 \mathrm{H}$}

Oxford: [...] contiene diversas formas de expresión, además de distintas formas de usar el sitio en la que se puede interactuar leyendo, escuchando y elaborando ejemplo de cómo y dónde se puede utilizar [...]

\section{Texto $17 \mathrm{H}$}

Oxford: Pondremos un ejemplo de búsqueda con la palabra "get" y ver las herramientas que el diccionario ofrece. Empezamos con una herramienta muy servible: "LISTENING" Y PRONUNCIATION"

Los estudiantes requerían acostumbrarse a identificar integralmente los recursos digitales prácticos de consulta, la valoración de la información, el diseño, la coherencia, las posibilidades de interactividad dialógica y el manejo de las herramientas del equipo y sus funciones. En suma, requerían el desarrollo de las prácticas integrales de textualidad digital en sus manifestaciones multimedia y multimodal (Álvarez, González y Bassa, 2017). 


\subsection{Recursos de cohesión digital en los apuntes sobre los diccionarios en línea}

La consideración de la cohesión para caracterizar los apuntes en el procesador de textos, permitió proponer categorías para estudiar prácticas multimodales de textualidad digital en la toma de apuntes. De esta forma, fue posible ampliar y contextualizar los estándares o criterios clásicos de textualidad (De Beugrande y Dressler, 1997), en las situaciones multimodales de escritura digital. La Tabla 2 muestra los desempeños relacionados con la cohesión en la interrelación de recursos discursivos digitales de naturaleza expositiva y descriptiva, y los de intertextualidad y referencialidad en los apuntes.

Tabla 2

Recursos de cohesión digital en los apuntes sobre los diccionarios en línea

\begin{tabular}{ll}
\hline Recursos de discursividad digital & $\begin{array}{l}\text { Ocurrencias en los apuntes digi- } \\
\text { tales }\end{array}$ \\
\hline Expositivo-descriptivo & $18(1,2,3,4,5,6,7,8,9,10,11$, \\
& $12,13,14,15,16,17,18)$ \\
\hline Intertextualidad mediante ilustraciones & $13(2,6,7,8,9,10,11,12,13,14$, \\
& $15,16,17,18)$, \\
\hline Intertextualidad mediante hipervínculos & $3(3,7,12)$ \\
\hline Referencialidad léxica a lo redactado & $7(2,3,6,10,11,13,17)$, \\
\hline Referencialidad léxica a las ilustraciones & $6(10,11,1213,15,17,18)$ \\
\hline Referencialidad gráfica & $3(10,12,17)$ \\
\hline
\end{tabular}

La predominante escritura expositiva y descriptiva incluye textos de alumnos que únicamente emplearon este tipo de redacción (textos: 1, 4, 5), es decir, omitieron las herramientas digitales de intertextualidad y referencialidad mediante ilustraciones, hipervínculos y recursos gráficos, así como aquellos que, empleando estos recursos, no los vincularon con la estructuración y recursos de cohesión digital. Estos resultados ponen de manifiesto que para la toma de apuntes sobre los diccionarios en línea, los alumnos aún requerían desarrollar la textualidad digital mediante la coexistencia multimodal de recursos cohesivos sintácticos, discursivos, gráficos y vínculos a distintas fuentes de información, en las perspectivas contempladas por Edwards-Groves (2010), Olza (2014) y Cordón (2016). En el siguiente ejemplo predomina la redacción expositiva y descriptiva correspondiente a recursos multimedia en los diccionarios consultados. 
Prácticas de textualidad digital de bachilleres al tomar notas sobre diccionarios en línea en la mediateca de lenguas

ERnesto Hernández RodríGuez

\section{Texto $8 \mathrm{M}$}

Cambridge Dictionary: [...] El sitio está en español, el idioma de la región lo cual puede facilitar la exploración a través de él. De igual forma cuenta con otros idiomas, incluso unos no tan populares como el catalán. Tiene una sección de blogs en donde hay artículos de diversos temas, también cuenta con la palabra más buscada o popular y una sección de palabras nuevas. El buscador es fácil de encontrar y la palabra también cuenta con pronunciación y el uso de la palabra junto con otras aunque no dice en sí lo que la palabra es. [...]

La alumna relacionó intertextualmente su apunte mediante imágenes seleccionadas para ejemplificar, y mostró habilidad en la interactividad operativa de las herramientas digitales: impresión de pantalla, copiado y edición de imágenes para ilustrar el significado del verbo get, tal como podemos apreciar en la Figura 1. Sin embargo, no estableció relaciones de cohesión entre la redacción y la imagen proporcionada, ya que no logró describir, comentar ni hacer transiciones ni referencias concretas a los contenidos; únicamente mencionó que el diccionario cuenta con pronunciación.

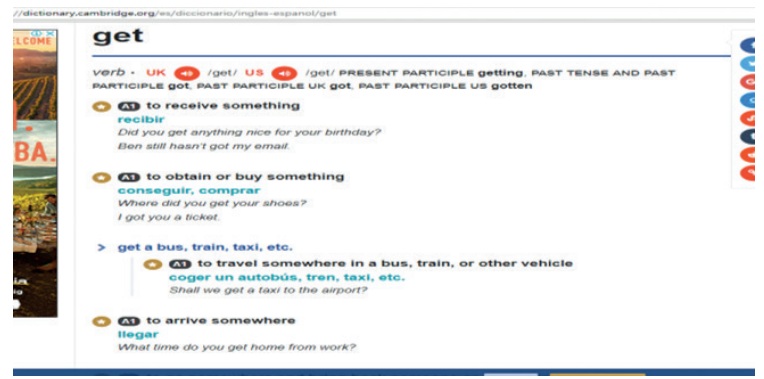

Figura 1. Recorte de impresión de pantalla para ubicar algunos significados del verbo get.

Sobre el criterio textual de adecuación en ambiente escolar, predominan las dificultades de acentuación, ortografía, segmentación de palabras y escritura descuidada mediante el uso del teclado. Los estudiantes presentaron dificultad con la interactividad mecánica sobre el funcionamiento del corrector del procesador de textos; únicamente 5 alumnos lograron resolver la ortografía y la segmentación de palabras (textos: 3, 5, 6, 11 y 14). El siguiente fragmento ejemplifica estas dificultades. 


\section{Texto $15 \mathrm{H}$}

Cambrige Dictionary: [...] Al ingresar encontraremos un menu principal donde encontraremos el diccionario un traductor y un apartado de gramatica.

Despues un espacio donde podras buscar palabras tanto en español como en ingles

Abajo encontraras diferentes articulos que te pueden interesar asi como ligas [...]

En los apuntes destaca la productividad de las relaciones de intertextualidad digital mediante ilustraciones (textos: 13 de 18). La Figura 2, correspondiente al texto $2 \mathrm{M}$, presenta la consulta de una tabla en el diccionario Wordreference sobre los significados y usos del verbo get y la selección de información para ilustrar el apunte, mediante las prácticas de copiar, pegar, resaltar fragmentos en color amarillo y reducir la tabla en Word.

\begin{tabular}{|c|c|c|}
\hline 1. get [sth] $v t r$ & informal (obtain) & conseguir $\Rightarrow v t r$ \\
\hline & & obtener $\Rightarrow v t r$ \\
\hline & \multicolumn{2}{|c|}{ We need to get some beer somewhere. } \\
\hline & \multicolumn{2}{|c|}{ Tenemos que conseguir cerveza en alguna parte. } \\
\hline \multirow[t]{3}{*}{ 2. get $v i$} & informal (arrive) & llegar $\Rightarrow v i$ \\
\hline & \multicolumn{2}{|l|}{ When will we get there? } \\
\hline & \multicolumn{2}{|l|}{ ¿Cuánto falta para Ilegar? } \\
\hline \multirow[t]{6}{*}{ get [sth] $v t r$} & informal (earn, win) (calificación) & sacar $\Rightarrow v t r$ \\
\hline & & ganar $\Rightarrow v t r$ \\
\hline & & obtener $\Rightarrow v t r$ \\
\hline & \multicolumn{2}{|l|}{ I got an $\mathrm{A}$ in Spanish. } \\
\hline & \multicolumn{2}{|c|}{ Saqué un 10 en español. } \\
\hline & \multicolumn{2}{|c|}{ (i) Ganó el primer premio en el concurso. } \\
\hline
\end{tabular}

Figura 2. Recorte de impresión de pantalla y fragmentos resaltados de un cuadro sobre significados del verbo get en el diccionario Wordreference.

La alumna contempló la hipertextualidad en el copiado de enlaces ubicados en la traducción y el tipo de verbo (transitivo o intransitivo). Además, copió y pegó contenidos sin la revisión cuidadosa, ya que presentó información incompleta en el fragmento "Ganó el primer premio en el concurso". Este contenido no corresponde a ninguna traducción en el texto copiado.

En contraste, en la Tabla 2 destaca el reducido manejo de recursos de 
Prácticas de textualidad digital de bachilleres al tomar notas sobre diccionarios en línea en la mediateca de lenguas

ERnesto Hernández Rodríguez

intertextualidad mediante hipervínculos (textos: 3 de 18) para el acceso a la diversidad de fuentes textuales. Esta situación implica la necesidad de reconocer las posibilidades de este recurso digital, es decir, la interrelación de intertextualidad con diversas fuentes textuales (Cerić, 2013) y la interactividad mecánica (Coyle y Thorson, 2001; Mayer, 2002) en el entorno digital.

El siguiente fragmento ejemplifica la interrelación de la redacción expositiva y descriptiva con relaciones de intertextulaidad mediante hipervínculos a cada diccionario. La alumna relacionó su apunte con la fuente en línea y contempló la hipertextualidad para acceder al texto directamente.

\section{Texto $3 \mathrm{M}$}

Oxford learner's dictionaries:

[...] https://www.oxfordlearnersdictionaries.com/us/definition/english/condition_1

Es un diccionario con conceptos variados los cuales dan un mejor entendimiento a las palabras, incluso da ejemplos que nos dan la idea de cómo se puede utilizar. [...]

Por otra parte, la referencialidad es fundamental para la cohesión textual digital, ya que permite remitirnos a determinada información mediante recursos léxicos y digitales. En el contexto digital, la cohesión implica complementar los criterios y herramientas clásicas gramaticales y léxicas estudiadas por Halliday y Hassan (1976) y De Beugrande y Dressler (1997). Para ello, se requiere el manejo de elementos gráficos que permitan establecer referencias a determinada información o hipervínculos. Los resultados muestran que la referencialidad léxica y gráfica no resultó ser un recurso productivo en los apuntes de los estudiantes.

La referencialidad léxica a lo redactado (7 de 20) permitió relacionar la información de manera intratextual en los apuntes. El siguiente ejemplo presenta recursos de referencialidad léxica a lo redactado previamente sobre los diccionarios consultados. Asimismo, la Figura 3 ilustra la selección de elementos generales de la conjugación, incluida la pronunciación. 


\section{Texto $6 \mathrm{M}$}

Cambridge Dictionary: [...] Éste a diferencia de los dos anteriores, el idioma en el que está el buscador es en español, también te presenta traducciones en español-portugués. [...] También presenta la conjugación y la manera en la cual está conjugado el verbo. [...]

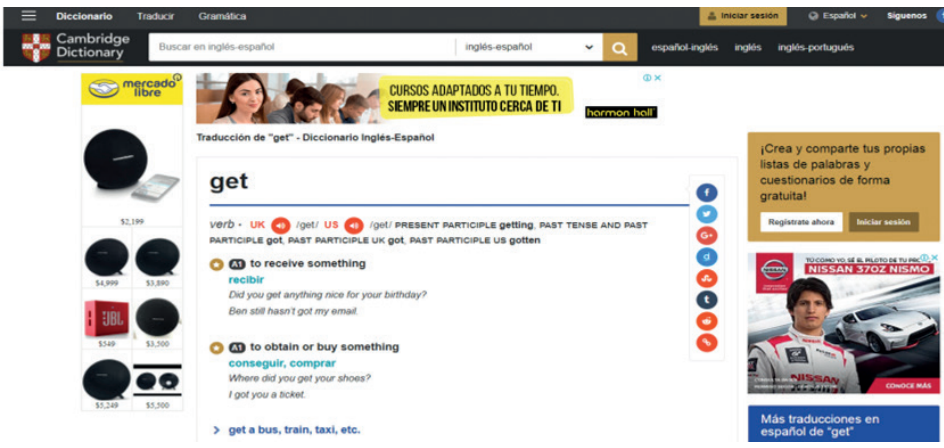

Figura 3. Impresión de pantalla sobre elementos generales de la conjugación del verbo get en el Cambridge Dictionary.

El siguiente ejemplo presenta referencias léxicas para describir el contenido del Merriam Webster Dictionary, ilustrado en la Figura 4.

\section{Texto $15 \mathrm{M}$}

Merriam Webster: En la parte superior encontraremos un menú que nos Ilevará a diferentes apartados como:

\section{JOIN MWU GAMES BROWSE THESAURUS WORD OF THE DAY VIDEO WORDS AT PLAY FAVORITES}

Al igual que encontraremos sus diferentes redes sociales para poder contactarlos o informarnos de sus publicaciones

Después encontramos algunos anuncios [...] noticias y actualizaciones de la página que podemos consultar dando click sobre ellas

Entre los anuncios y el menú superior encontraremos un espacio donde podrás ingresar alguna palabra que quieras saber su significado

Al ingresar la palabra get encontrarás su significado, así como diferentes ejemplos donde es empleada la palabra y algunas observaciones sobre su gramática 
Prácticas de textualidad digital de bachilleres al tomar notas sobre diccionarios en línea en la mediateca de lenguas

ERnesto HeRnández Rodríguez

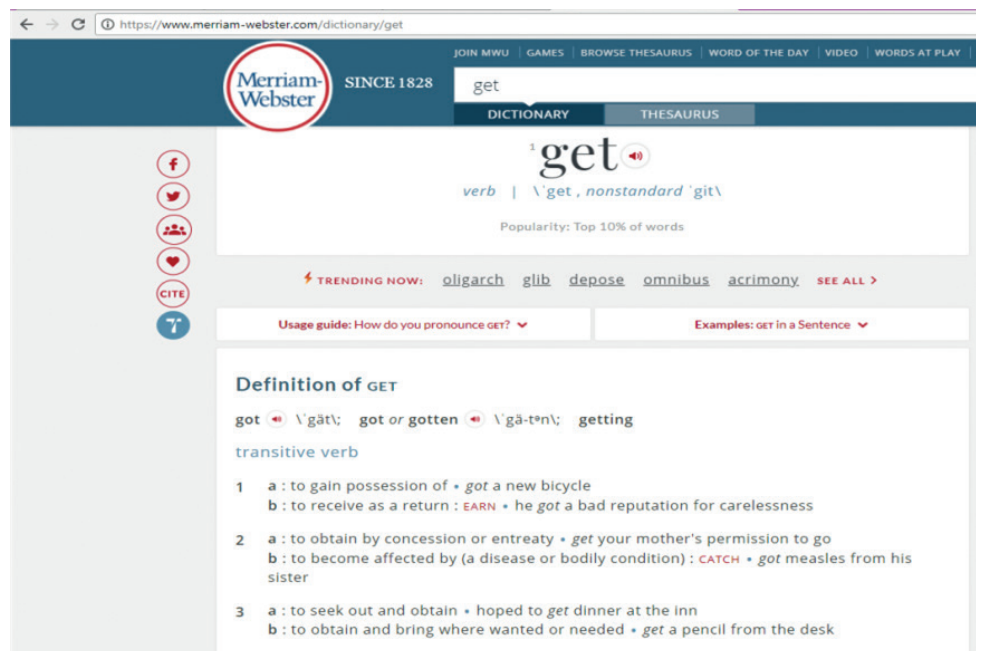

Figura 4. Impresión de pantalla sobre elementos generales de la conjugación del verbo get en el Merriam Webster Dictionary.

En el siguiente ejemplo, el alumno relacionó elementos de informatividad y recursos gráficos para referirse a imágenes del diccionario que podemos apreciar en las Figuras 5 y 6 . Los contenidos corresponden al acceso a la información y los recursos multimedia. La redacción se acompaña de referencias gráficas a determinados contenidos, mediante colores que relacionan la información escrita y el circulado de los contenidos considerados.

\section{Texto $10 \mathrm{H}$}

\section{Oxford Leaerner's Dictionaries.}

[...] al poner una palabra automáticamente te dice qué tipo de palabra es, también nos da algunos consejos útiles que deberíamos saber para implementarlos, cómo pronunciarlos correctamente; también algunas otras formas de las palabras, verbos, pronombres, etc., otros resultados en caso de algún error y lo mejor es que hasta ejemplos nos incluye. También usa la palabra buscada con otras palabras y cómo se relaciona con ésta y como puede ser utilizada en estos cambios y la variación de su significado en estos casos. La mayoría de los modismos que se relacionan con la palabra etc. 


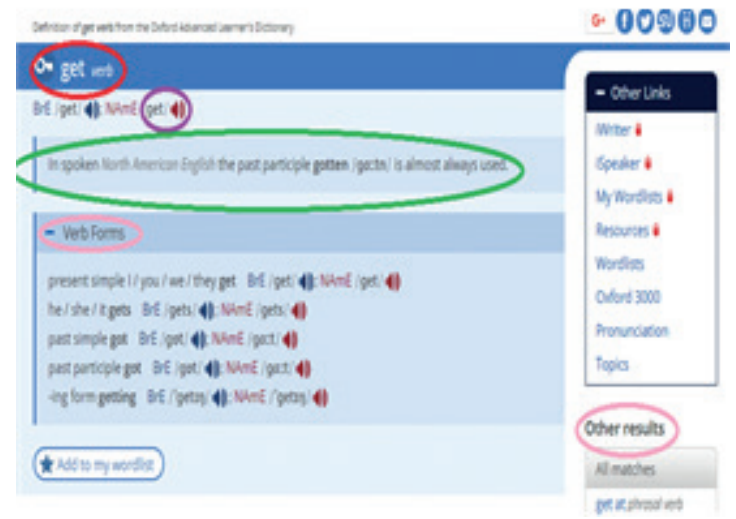

Figura 5. Selección de información mediante recursos gráficos de circulado en colores.

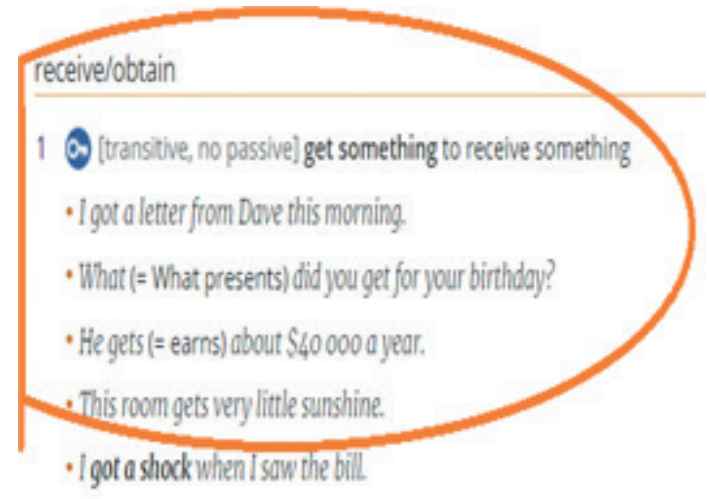

Figura 6. Selección de significados específicos del verbo get mediante el recurso gráfico de circulado.

Este ejemplo evidencia la relación de intertextualidad digital entre el apunte y el diccionario y las prácticas de operatividad mecánica requeridas para los recursos gráficos.

\subsection{Intencionalidad en la integración de recursos de escritura digital en los apuntes}

El mayor avance en los apuntes sobre los diccionarios en línea se aprecia en los textos con un manejo integral de los recursos multimodales de cohesión digital y los elementos de informatividad pertinentes sobre las fuentes consultadas. Sobre el desempeño en el manejo de recursos de cohesión para la expresión escrita, tal como plantea Salas (2011), 
Prácticas de textualidad digital de bachilleres al tomar notas sobre diccionarios en línea en la mediateca de lenguas

ERnesto Hernández Rodríguez

la "abundancia de elementos de referencialidad personal anafórica, así como de conectores aditivos y causales, no garantizan la producción de un texto cohesionado" (p. 29). Además, los resultados muestran que no bastaba emplear diversos recursos digitales multimedia y multimodales para un mejor desempeño. Por ejemplo, el texto $2 \mathrm{M}$ presenta claridad en los contenidos y la cohesión, únicamente mediante la redacción expositiva y descriptiva. El Anexo 1 presenta un fragmento de este apunte digital.

El apunte $11 \mathrm{M}$ presenta avance para organizar, de manera interrelacionada y con transiciones dinámicas, la redacción expositiva y descriptiva, y las relaciones de intertextualidad y referencialidad mediante imágenes para ilustrar lo redactado. Los contenidos abordan aspectos de textualidad digital sobre el acceso a la información y los recursos multimedia en los diccionarios. El Anexo 2 presenta un pasaje representativo del apunte.

El apunte $3 \mathrm{M}$ presenta la integración de recursos de redacción digital mediante un diseño y estructuración sistematizada y uniforme de los contenidos en el procesador de textos, favoreciendo la cohesión y la coherencia textual. Asimismo, apreciamos la necesidad de la revisión y la edición en la información copiada. La alumna utilizó el recurso discursivo expositivo y, en menor medida, el descriptivo, con vínculos a cada diccionario. Además, consideró la intertextualidad al relacionar su escrito con la fuente en línea y la hipertextualidad para acceder al texto. Por ello, este apunte ejemplifica un desempeño que integra diversas literacidades digitales (Lea y Jones, 2010; Blikstad-Balas, 2015; Álvarez, González y Bassa, 2017). El Anexo 3 presenta un pasaje representativo de este apunte.

En el Merriam-Webster, la alumna identificó herramientas multimedia en "diferentes videos y juegos que ayudan a la comprensión de los conceptos" y estableció la intertextualidad y referencialidad al comparar "los otros diccionarios", "el primero que revisé" y "los contenidos del otro". En el Merriam-Webster Visual Dictionary, destacó el recurso multimedia para facilitar el entendimiento y contempló la hipertextualidad al referirse a los "conceptos de otro sitio".

En suma, podemos establecer que para lograr el avance en la escritura digital, lo relevante era relacionar e integrar los diversos recursos digitales empleados, de manera cohesiva y coherente. Observamos este tipo de desempeño en únicamente 6 textos $(3 \mathrm{M}, 11 \mathrm{M}, 12 \mathrm{M}, 13 \mathrm{H}, 15 \mathrm{H}, 17 \mathrm{H})$. 


\section{Conclusiones}

El estudio de las prácticas de textualidad al tomar apuntes digitales sobre diccionarios en línea, muestra diversas consideraciones de los estudiantes en la identificación de recursos multimedia y modalidades textuales y digitales. El trabajo permitió caracterizar el desempeño en la perspectiva de la intencionalidad en las diversas prácticas de literacidades digitales (Lea y Jones, 2010; Blikstad-Balas, 2015). Los estudiantes no estaban acostumbrados al uso de estas fuentes de consulta ni a la toma de apuntes en el procesador de textos; la práctica realizada les resultó de utilidad para tener una visión panorámica de las características de los diccionarios y para experimentar diversas prácticas digitales en la toma de apuntes.

Las actividades de lectura y escritura digital para tomar apuntes sobre los diccionarios en línea implicaron desarrollar hábitos y estrategias relacionadas con los estándares de textualidad (De Beugrande y Dressler, 1997), y con las prácticas de textualidad multimodal digital (Álvarez, González y Bassa, 2017), en este caso, en la toma de apuntes sobre los diccionarios (Johnson y Nádas, 2009; Stacy y Cain, 2015). Esta integración de recursos textuales propició, en diferentes niveles de desempeño, el enriquecimiento de repertorios lingüísticos y discursivos relacionados con la propuesta de criterios de textualidad multimodal de esta investigación: informatividad, coherencia, cohesión, intertextualidad, diseños textuales, interactividad dialógica, interactividad mecánica, intencionalidad y adecuación.

La identificación de las funciones fundamentales en los diccionarios (usos de la lengua, consultas digitales y recursos multimedia) muestra el énfasis práctico en el manejo de los contenidos. Los alumnos mostraron distintos niveles de intencionalidad en el desempeño en las posibilidades multimedia y multimodal, a pesar del menor avance en la valoración de la coherencia, la intertextualidad, el diseño textual y la interactividad dialógica y mecánica. Esta situación manifiesta que el desarrollo de prácticas de literacidad digital implica un proceso gradual de experimentación de recursos multimodales de lectura y escritura. El mayor avance en el desempeño corresponde a quienes lograron apreciar integralmente la multiplicidad de elementos de informatividad en los diccionarios.

En posteriores investigaciones, esta propuesta de caracterización tex- 
Prácticas de textualidad digital de bachilleres al tomar notas sobre diccionarios en línea en la mediateca de lenguas

ERnesto Hernández Rodríguez

tual digital, puede ser útil para estudiar el uso de las fuentes de consulta y para propiciar la revisión integral de estos textos en línea. Su aplicación puede adaptarse a distintos entornos y propósitos educativos relacionados con el fortalecimiento de las prácticas de literacidad multimedia y multimodal, con las debidas adaptaciones en distintos contextos educativos.

En virtud de que en los apuntes observamos un reducido manejo integral de la diversidad de recursos de escritura digital, lo relevante era caracterizar los intentos por emplear la variedad de posibilidades multimodales de textualidad. Los estudiantes requerían desarrollar prácticas cohesivas de intertextualidad, mediante hipervínculos para relacionar la redacción expositiva y descriptiva con las fuentes textuales y las referencias léxicas y gráficas a determinada información. Este tipo de prácticas de textualidad digital implica la coexistencia multimodal de recursos sintácticos, gráficos, discursivos (Edwards-Groves, 2010; Olza, 2014; Cordón, 2016) e intertextuales para establecer referencias con distintas fuentes multimodales de textualidad y propiciar la interactividad digital y las relaciones dialógicas (Cerić, 2013).

La expresión expositiva y descriptiva muestra las dificultades para la escritura con la herramienta de corrección mediante el procesador de textos y para integrar los recursos digitales. Para lograr la escritura cohesiva y coherente con recursos de intertextualidad y referencialidad, mediante ilustraciones, hipervínculos y expresiones gráficas, era necesario desarrollar estrategias integrales de textualidad digital. Además, la mayor productividad en las relaciones de intertextualidad mediante ilustraciones, copiadas de los diccionarios, se manifestó, en su mayoría, sin relaciones cohesivas con la redacción. Estos resultados, son relevantes por la necesidad de desarrollar actividades que propicien el desarrollo gradual e integral de las prácticas de literacidad digital en ambientes académicos.

El estudio muestra que no era suficiente usar diversos recursos multimedia y multimodales para un mejor desempeño en la escritura digital. De este modo, en contexto escolar, no resulta favorable fomentar el manejo abundante y descontextualizado de recursos discursivos y digitales mediante las nuevas tecnologías; lo relevante es propiciar su uso integrado de manera significativa con los elementos de informatividad y cohesión discursiva pertinentes.

La metodología empleada fomenta la revisión crítica de los dicciona- 
rios, los recursos de textualidad digital, las herramientas en el procesador de textos, las opciones multimedia y multimodal, la revisión y la edición textual. El método de clasificación y de análisis aporta la contextualización de los estándares clásicos de textualidad en el marco de la literacidad digital. La propuesta de categorías de textualidad digital favoreció la caracterización de las prácticas involucradas en la toma de apuntes sobre los diccionarios. El criterio de cohesión permitió describir el predominio de las prácticas de redacción expositiva y descriptiva y las de textualidad digital, principalmente, para el establecimiento de referencias y relaciones de intertextualidad a múltiples contenidos multimodales. Asimismo, la consideración de la intencionalidad en el desempeño, permite contemplar los avances de los estudiantes al tratar de integrar los recursos de textualidad digital en los apuntes sobre los diccionarios. En futuras investigaciones, el método de clasificación y análisis textual puede ser adaptado para estudiar distintas prácticas multimedia y multimodales en múltiples contextos de literacidad digital.

\section{Referencias}

Álvarez, G.; González, A. y Bassa, L. (2017). Apuntes para pensar la apropiación de tecnologías en la enseñanza de la lectura y la escritura. En R. Cabello y A. López (Eds.), Contribuciones al estudio de procesos de apropiación de tecnologías (pp. 227-239). Buenos Aires: Ediciones del Gato Gris y Red de Investigadores sobre Apropiación de Tecnologías. Recuperado de https://www.aacademica.org/anahi.mendez/55.pdf

Bausela-Herreras, E. (2007). Relación entre autorregulación y autoconocimiento de la escritura con la coherencia y productividad de un texto. Cuestiones pedagógicas, 18, 257-270.

Blikstad-Balas, M. (2015). Digital Literacy in Upper Secondary School - What do students use their laptops for during teacher instruction? Nordic journal of digital literacy, 10, 9.

Cerić, V. (2013). Digital text: interactivity and intertextuality. Online Journal of art and design, 1(1): 17-31. Recuperado de http://www.adjournal.net/articles/11/113.pdf

Coyle, J. y Thorson, E. (2001). The effects of progressive levels of interactivity and vividness in web marketing sites. Journal of Advertising, 30(3), 13-28.

Cordón, J. A. (2016). La lectura en el entorno digital: nuevas materialidades y prácticas discursivas. Revista chilena de literatura, 94, 15-38.

De Beugrande, R. y Dressler, W. (1997). Introducción a la lingüística del texto. Barcelona: Ariel-Lingüística.

Edwards-Groves, C. J. (2010). The multimodal writing process: changing practices in contemporary classrooms. Language and education, 25(1), 49-64. Recuperado de https://www.tandfonline.com/doi/abs/10.1080/09500782.2010.523468 
Prácticas de textualidad digital de bachilleres al tomar notas sobre diccionarios en línea en la mediateca de lenguas

ERnesto Hernández RodríGuez

Gass, S. M. y Mackey, A. (2007). Data elicitation for second and foreign language research. Mahwah: Lawrence Erlbaum Associates.

Gurr, C. A. (1999). Effective Diagrammatic communication: syntactic, semantic and pragmatic issues. Journal of visual languages and computing, 10, 317-342.

Halliday, M. A. K. y Hassan, R. (1976). Cohesion in English. Londres: Longman.

Hernández, E. y Reyes, E. (2015a). Interactividad y textualidad digital para elaborar materiales multimedia con canciones para el aprendizaje de la lengua extranjera en la mediateca del bachillerato. ReLingüística aplicada, 11(17), 7.

Hernández, E. y Reyes, E. (2015b). Manual de recursos para la redacción bilingüe. En Recomendación de textos en inglés y español. Recuperado de: https://recomendacionesbilingues.blogspot.com/2015/10/800x600-normal-0-21-false-false-false_93.html

Hyland, K. (2005), Metadiscourse: exploring interaction in writing. Londres: Continuum.

Hyland, K. (2016). Methods and methodologies in second language writing research. System, 59, 116-125.

Jewitt, C. (2006). Multimodality, "Reading", and "Writing" for the 21st century. Discourse: studies in the cultural politics of education, 26(3), 315-331. Recuperado de:

https://doi.org/10.1080/01596300500200011

Johnson, M. y Nádas, R. (2009). Marginalised behaviour: digital annotations, spatial encoding and the implications for reading comprehension. Learning, media and technology, 34(4), 323-336.

Lea, M. R. y Jones, S. (2010). Digital literacies in higher education: exploring textual and technological practice. Studies in higher education, 36(4), 377-393.

López, M. (2017). Buscar, evaluar y seleccionar información digital: una experiencia didáctica en educación secundaria (Tesis doctoral, Mondragon Unibertsitatea). Recuperado de http://academica-e.unavarra.es/bitstream/handle/2454/26022/Tesis\%20 Maite \%20L\%C3\%B3pez\%20Flamarique.pdf?sequence=1 \&isAllowed=y

Mayer, E. R. (2002). Cognitive theory and the design of multimedia instruction: An example of the two-way street between cognition and instruction. New directions for teaching and learning, 89, 55-71. Recuperado de: http://onlinelibrary.wiley.com/ doi/10.1002/tl.47/abstract

Olza, I. (2014). Nuevas tecnologías y procesos de lectura/escritura: panorama y aplicaciones. En A. Baraibar (Ed.), Humanidades Digitales: una aproximación transdisciplinar (pp. 85-98). Coruña: SIELAE-JANUS.

Oxford, R. (1990). Language learning strategies: What every teacher should know. Boston: Heinle \& Heinle/Cengage.

Salas, C. (2011). Los elementos cohesivos en el discurso académico escrito: una experiencia desde el contexto universitario. Legenda, 15(13), 29-55.

Sarena, N. (2006). Los jóvenes e internet: experiencias, representación, usos y apropiaciones de internet en los jóvenes. UNIrevista, 1(3), 1-11.

Serrano-Puche, J. (2013). Vidas conectadas: tecnología digital, interacción social e identidad. Historia y Comunicación Social, 18, 353-364. Recuperado de: http://revistas.ucm.es/index.php/HICS/article/viewFile/44249/41810

Stacy, E. M. \& Cain, J. (2015). Note-Taking and Handouts in The Digital Age. American Journal of Pharmaceutical Education, 79(7), 107. 
Prácticas de textualidad digital de bachilleres al tomar notas sobre diccionarios en línea en la mediateca de lenguas ERnesto HeRnández RodríGuez

Tyrkkö, J. (2007). Making sense of digital textuality. European journal of English studies, 11(2), 147-161. Recuperado de:

https://www.tandfonline.com/doi/pdf/10.1080/13825570701452722?needAccess=tr ue

Waller, R. (2012). Graphic literacies for a digital age: The survival of layout. The Information society, 28(4), 236-252.

Wenden, A. (1986). Helping language learners think about learning. ELT journal. An international journal for teachers of English to speakers of other languages, 40(1), 161-175.

Whitman, L. (2009). The Effectiveness of interactivity in computer-based instructional diagrams. En Jacko, Julie A. (Ed.), Human computer interaction, 2, 889-908.

\section{Anexos}

\section{Anexo 1}

\section{Texto $2 \mathrm{M}$}

Oxford learner's Dictionaries: es un diccionario muy completo ya que contiene un pequeño fragmento de las palabras las reglas en donde se deben de usas, las circunstancias, las formas necesarias en donde se debe de utilizar la palabra, su pronunciación en dos diferentes voces y también en su buscador tiene opciones de las formas de pronunciación o de las palabras en diferentes formas. Tiene una página en donde te explica la forma de pronunciación de cada palabra y clasifica a las palabras como consonantes, diptongos, entre otros. La misma página de Oxford te abre algunos ejercicios para que practicar la gramática.

\section{Anexo 2}

\section{Texto $11 \mathrm{M}$}

\section{OXFORD LEARNER'S DICTIONARIES}

http://recomendacionesbilingues.blogspot.mx/2015/10/800x600-normal0-21-false-false-false_93.html

Las herramientas de ayuda que el Oxford Learner's Dictionaries ofrece a sus usuarios son las siguientes: 
Prácticas de textualidad digital de bachilleres al tomar notas sobre diccionarios en línea en la mediateca de lenguas

ERnesto HeRnández Rodríguez

Tipo de palabra que es (verbo, sustantivo,etc.)

\section{Om get verb}

Figura 7. Hipervínculo a significados.

Ofrece una demostración de la pronunciación de la palabra.

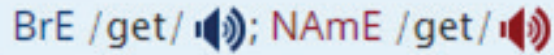

Figura 8. Opciones de pronunciación.

Algunas veces incluye una nota para dejar en claro alguna diferencia entre el inglés de Reino Unido y E.E.U.U.

In spoken North American English the past participle gotten /ga:tn/ is almost always used.

Figura 9. Distinciones de pronunciación.

Si la palabra es un verbo, se puede acceder a la conjugación y a la demostración de la pronunciación.

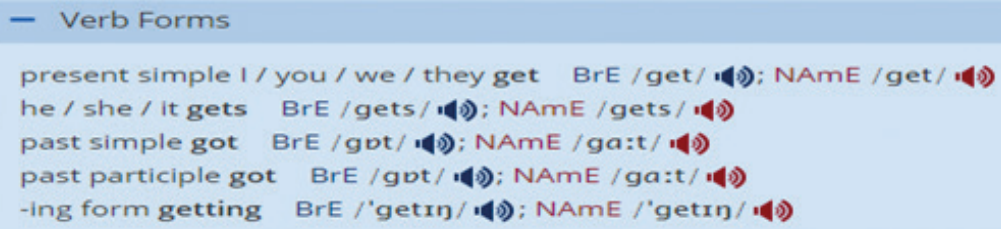

Figura 10. Conjugación y pronunciación.

Cuando hay muchas palabras que podrían tener un significado semejante pero que por cuestiones gramaticales se pueden usar únicamente en determinadas ocasiones, la opción "Which Word?" ofrece una explicación para esto. 


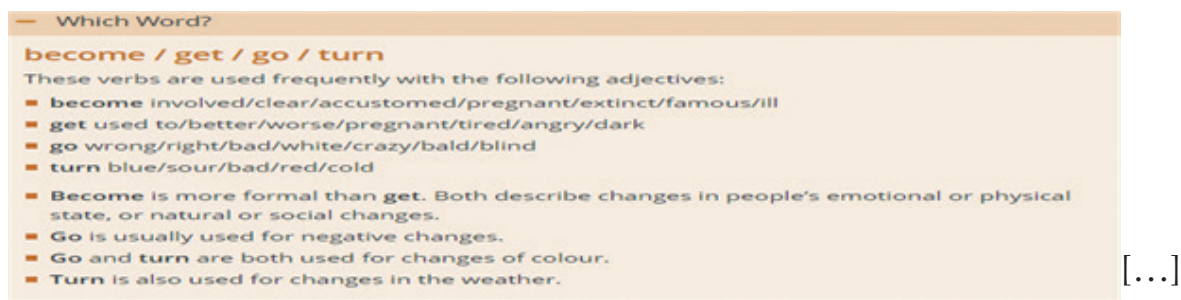

Figura 11. Selección de múltiples significados del verbo get.

\section{Anexo 3}

\section{Texto $3 \mathrm{M}$}

Oxford learner's dictionaries

https://www.oxfordlearnersdictionaries.com/us/definition/english/condition_1

Es un diccionario con conceptos variados los cuales dan un mejor entendimiento a las palabras, incluso da ejemplos que nos dan la idea de cómo se puede utilizar.

Get something to receive something.

- I got a letter from Dave this morning.

- What (= What presents) did you get for your birthday?

- He gets (=earns) about $\$ 40000$ a year.

Pude notar claramente que el verbo se utiliza para recibir, obtener y hacer algo. [...]

\section{Merriam-Webster \\ https://www.merriam-webster.com/dictionary/}

Contiene diferentes definiciones, definiciones etimológicas, sinónimos, antónimos y ejemplos, los cuales nos dan a entender lo que se dice en cada concepto, además de esto podemos encontrar diferentes videos y juegos que ayudan a la comprensión de los conceptos.

Get is a Transitive verb

*to gain possession of got a new bicycle, to receive as a return: earn *he got a bad reputation for carelessness [...] 
Prácticas de textualidad digital de bachilleres al tomar notas sobre diccionarios en línea en la mediateca de lenguas

ERnesto Hernández RodríGuez

Wordreference.com

http://www.wordreference.com/es/translation.asp?tranword=travel

Este diccionario no solo nos da los conceptos básicos y su utilización, también nos da la definición de componerlos con otras palabras, lo que hace su significado diferente.

get [sth] vtr informal (obtain) $\quad$ conseguir $\Rightarrow$ vtr obtener $\Rightarrow \operatorname{vtr}[\ldots]$

Oxford Dictionaries

https://en.oxforddictionaries.com/definition/

Este diccionario no tiene conceptos variados ni bastantes ejemplos, pero viene ordenado y es fácil entenderlo.

GET Usage: The verb get is in the top five of the most common verbs in the English language. Nevertheless, there is still a feeling that almost any use containing get is somewhat informal. No general informal label has been applied to this dictionary entry, but in formal writing it is worth bearing this reservation in mind [...] 